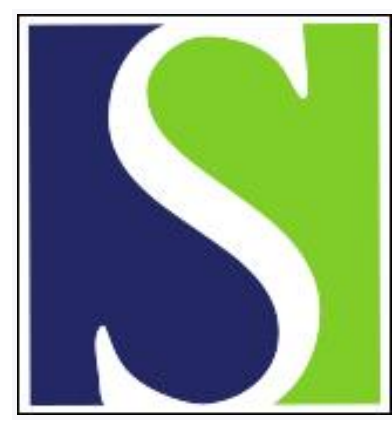

Scand J Work Environ Health 1984;10(6):517-519

https://doi.org/10.5271/sjweh.2291

Issue date: Dec 1984

Effects of job change on job satisfaction and mental strain.

by Kirjonen J, Hanninen V

The following article refers to this text: 2023;49(2):95-98

This article in PubMed: www.ncbi.nlm.nih.gov/pubmed/6535255

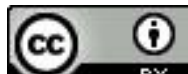




\title{
Effects of job change on job satisfaction and mental strain
}

\author{
by Juhani Kirjonen, DrE, Vilma Hänninen, MPoISc ${ }^{1}$
}

\begin{abstract}
KIRJONEN J, HÄNNINEN V. Effects of job change on job satisfaction and mental strain. Scand $J$ Work Environ Health 10 (1984) 517-519. The effect of improved work conditions on symptoms of mental strain was examined in a longitudinal study of metal industry employees. The aim was to study the changes in work conditions, job satisfaction, and indices of mental strain among the employees who were promoted or who changed employer in comparison to those who had stayed in the same job during the five-year follow-up period (matched groups, $N$ 136). During the study period, work content and physical work environment had significantly improved in the job-change group compared to the reference group. Job dissatisfaction, life dissatisfaction, and stress symptoms had decreased significantly in the job-change group. The most powerful predictors of changes in job stress or general mentai strain were changes in work content and changes in the quality of the physical work environment. However, the multiple correlations obtained in the regression analyses were not high.
\end{abstract}

Key terms: work satisfaction.

The aim of this study was to examine the effect of improvement in the work situation on mental wellbeing. The theoretical framework of the study was stress theory, according to which mental strain arises out of misfit between the individual's abilities and aspirations regarding work and the demands imposed and the supplies for need satisfaction provided by the job. We supposed that climbing upwards on the occupational ladder would mean an improvement in work conditions and that it would result in greater job satisfaction and reduced mental strain. We also assumed that a voluntary change of employer serves as a coping strategy which aims at reducing the misfit between a job and a person and that this change also would result in a decrease in job dissatisfaction and mental strain (1).

The study examines, on the basis of longitudinal data, (i) the antecedents to the obtainment of a better job, that is, any initial differences between those who have been promoted and those who have not, (ii) the consequences of job changes on employee evaluation of their work, on their job satisfaction and on mental strain, and (iii) kinds of changes in the work situation that are associated with changes in job satisfaction and mental strain.

\section{Methods}

The sample of the study was selected from among the personnel of a large metal-working company in cen-

1 Department of Public Health, University of Tampere, Tampere, Finland.

Reprint requests to: Dr J Kirjonen, Department of Public Health, University of Tampere, PO Box 607, SF-33101 Tampere, Finland. tral Finland. The population was stratified according to occupational status, gender, and age. The first phase of the study was carried out in 1973, and a follow-up study (phase II) was carried out five years later. The initial sample comprised 902 persons, out of which 748 participated also in the follow-up. In the subsequent analyses only those persons were included who participated in both phases and who were not retired in 1978. The size of the final sample was thus 657 persons.

The data from the two phases were collected by questionnaires containing identical items on different aspects of work conditions and mental strain (2). For the study of changes in job circumstances, two groups were formed: the job-change group $(\mathrm{N}=$ $136)$ and the no job-change (reference) group $(N=$ 136), which were matched by occupational status, gender, and age.

\section{Results}

The first step in the analysis was to compare the work conditions of the two groups during both phases of the study (figure 1). When we look at the differences in the first phase, we can see that the job-change group was initially different from the reference group only in certain respects. Those who had changed their job during the five-year follow-up period had previously regarded their job as less interesting and less demanding than those who had stayed in the same job. This finding suggests that the job-change group was somewhat selected with respect to their satisfaction with their previous jobs.

The effects of job change on work conditions were very favorable in respect to most of the dimensions. 


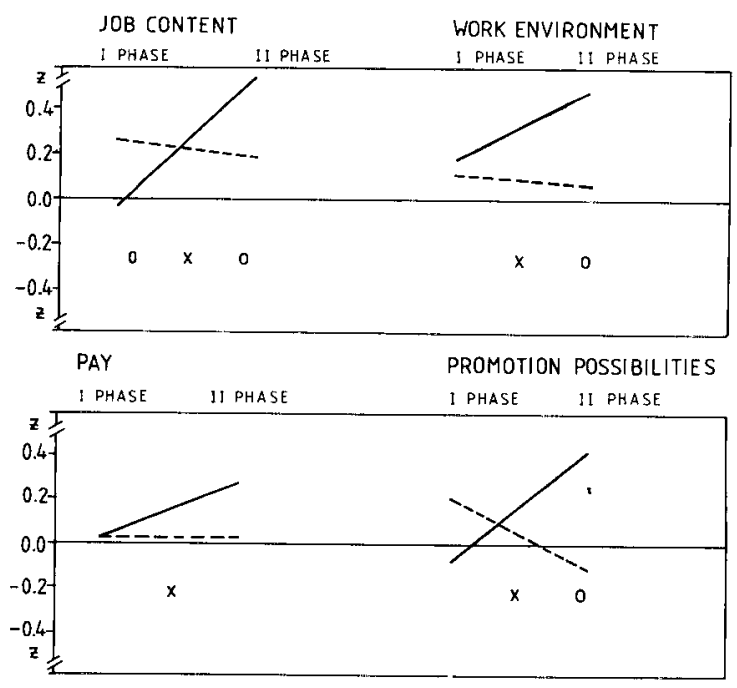

Figure 1. Means of the indices of work conditions for the jobchange and reference groups during the two phases of the study. Significant differences (Student's t-test): $0=$ $p<0.05$ between the groups during phase 1 or II. $x=$ $p<0.05$ between the index scores of the two groups. Scores are $z$-transformed; high values $=$ positive evaluations. $[-=$ job-change group $(\mathrm{N}=136),------$ $=$ reference group $(N=136)]$

Table 1. Regression analyses on changes of job stress and general mental strain using the score for the change in various work conditions as predictors.

\begin{tabular}{lll}
\hline & \multicolumn{2}{c}{ Beta coefficents } \\
\cline { 2 - 3 } Work condition & $\begin{array}{l}\text { General job } \\
\text { stress }\end{array}$ & $\begin{array}{l}\text { General mental } \\
\text { strain }\end{array}$ \\
\hline Job content & $-0.19^{* * *}$ & $-0.18^{* * *}$ \\
Work environment & $-0.18^{* * *}$ & $-0.11^{* * *}$ \\
Co-worker relations & -0.05 & 0.00 \\
Supervisor relations & $-0.12^{* * *}$ & $-0.07^{* *}$ \\
Job security & -0.00 & -0.01 \\
Access to information & 0.03 & -0.04 \\
Promotion Opportunities & -0.01 & 0.06 \\
Satisfaction with pay & -0.02 & 0.02 \\
\hline Numbér of subjects & 657 & 657 \\
Multiple correlation & 0.34 & 0.29 \\
coefficient & $10.7(p<0.001)$ & $7.4(p<0.001)$ \\
F-test statistic & \multicolumn{2}{l}{}
\end{tabular}

The clearest positive changes were seen in aspects of job content, such as skill utilization, autonomy, and variety, and also in the quality of the physicochemical work environment. The characteristics of the work conditions seem to be very intertwined in that job change involved all aspects of the work situation.

The next step was to compare the indicators of mental strain in the study groups. Looking again first at the initial differences, we found that life dissatisfaction and job dissatisfaction were somewhat higher in the job-change group than in the reference group (figure 2). This finding suggests that, in the jobchange group, there was a stressful discrepancy between aspirations and achievements in the job.

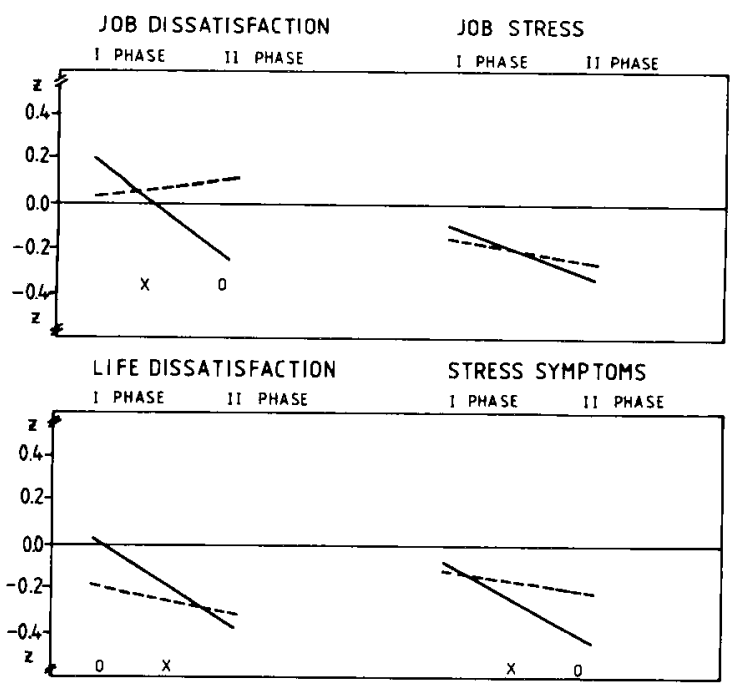

Figure 2. Means of the mental strain indicators for the jobchange and reference groups during the two phases of the study. Significant differences (Student's t-test): $0=$ $p<0.05$ between the groups during phase I or II, $x=$ $p<0.05$ between the scores of the indicators of the two groups. Scores are $z$-transformed; high values $=$ high mental strain. $[-$ reference group $(N=136)]$ group $\quad(N=136)$,

The effect of job change on mental well-being was positive. In the job-change group a marked reduction was found for almost all the indicators of mental strain, while the changes in the reference group were small. The only exception was job stress, for which the changes were not statistically significantly different between the two groups.

Finally we wanted to know which dimensions of the work conditions were the most strongly associated with changes in mental strain. This question was examined by regression analyses using the scores for the change in different aspects of the work conditions as independent variables and the scores for the change in mental strain as dependent variables. The whole study sample was used in these analyses.

The multiple correlations obtained in these analyses were statistically significant but not strong (table 1). The regression models explaining the changes in general mental strain and changes in general job stress were similar, a finding which suggests that these two phenomena were closely related. The most powerful predictors of changes in both of these variables were changes in job content, changes in the work environment, and changes in supervisor relations.

\section{Conclusion}

We might conclude, then, that work conditions seem to have a marked effect on mental well-being - not only on the feelings related to the work itself but also on affective and psychosomatic symptoms and on 
how the overall life situation is appraised. This finding allows for several slightly different interpretations. First, we might argue that an improvement in several aspects of the work conditions had reduced the stresses inherent in the previous job, especially by having improved the possibilities for self-actualization in the job. This interpretation supports the notions of occupational stress research (1).

Another possibility is to see job change as a life event that, as a positive change in itself, has reduced mental strain. This interpretation would be at variance with the traditional assumptions about life changes, according to which even desirable changes have a negative effect on mental well-being. And, third, we might emphasize the significance of the goal-striving activity of the individual, which infers that promotion or better employment, as an achievement of one's own goal, promotes mental health. Anyway, our conclusion is that, in industrial organi- zations, mental strain could be reduced by improvements in the possibilities for career development in "dead-end" jobs, by enrichment of the work content, and by improvement in the quality of the physicochemical work environment.

\section{References}

1. Harrison R Van. Person environment fit and job stress. In: Cooper CL, Payne R, ed. Stress at work. John Wiley Sons, New York, NY 1978.

2. Leino $\mathrm{P}$, Hänninen V, Toivonen $\mathrm{L}$, Aro S, Telama R, Kirjonen J, Hasan J. Työolot, psyykkinen hyvinvointi, elintavat ja terveydentila metalliteollisuuden ammattiasemaryhmissä 1973-83 (METELI) [Working conditions, mental well-being, living habits, and health among occupational groups in the metal industry in 1973-83]. University of Tampere, Tampere 1984. (Kansanterveystieteen julkaisuja M82/84). 